\title{
Thin-Layer Modeling and Determination of Effective Moisture Diffusivity and Activation Energy for Drying of Red Mud from Filter Presses
}

\author{
Panagiotis M. Angelopoulos ${ }^{1} \cdot$ Efthymios Balomenos $^{1} \cdot$ Maria Taxiarchou $^{1}$
}

Published online: 26 April 2016

(C) The Minerals, Metals \& Materials Society (TMS) 2016

\begin{abstract}
Red mud is generated during alumina production through Bayer process; it is the insoluble product obtained after bauxite digestion with sodium hydroxide at elevated temperature and pressure. In recent years, various attempts have been made to exploit red mud for the extraction of its valuable components or its usage in the fabrication of cement, ceramics, and other minor products; in all such cases, red mud drying constitutes a major preliminary processing stage that has not been studied in depth. In the current study, drying kinetics and energetics of red mud obtained from filter presses of Aluminum of Greece are studied. Drying experiments were performed under isothermal condition over a wide temperature range $\left(50-250{ }^{\circ} \mathrm{C}\right)$ and 10 thin-layer models were employed for simulation of temporal evolution of moisture removal. Three statistical error factors were implemented in order to test models' accuracy, and it was found that Midilli et al.'s equation showed the best fit $\left(R^{2}>0.99\right)$. Effective moisture diffusivity was estimated by diffusion model based on the Fick's second law and found to vary from $0.3510 \times 10^{-9}$ to $21.3951 \times 10^{-9} \mathrm{~m}^{2} \mathrm{~s}^{-1}$ at a drying temperature ranging from 50 to $250{ }^{\circ} \mathrm{C}$, respectively. The activation energy of red mud drying was found to have a value of $28.133 \mathrm{~kJ} \mathrm{~mol}^{-1}$.
\end{abstract}

Keywords Thin layer modeling · Red mud drying kinetics $\cdot$ Bauxite residue $\cdot$ Filter presses cake $\cdot$ Aluminum of Greece

The contributing editor for this article was Yiannis Pontikes.

Panagiotis M. Angelopoulos

pangelopoulos@metal.ntua.gr

1 Department of Mining and Metallurgical Engineering, National Technical University of Athens, Athens, Greece

\section{Introduction}

Bauxite residue or red mud is the solid waste residue obtained after the digestion of bauxite ores with caustic soda for alumina $\left(\mathrm{Al}_{2} \mathrm{O}_{3}\right)$ production through the Bayer process. On average, the Bayer process requires $2.65 \mathrm{~kg}$ of bauxite ore to produce $1 \mathrm{~kg}$ of alumina, while the slurry containing the remaining bauxite ore is removed from the thickeners during the liquor clarification stage [1]. Due to its ultra-fine granulometry, high alkalinity, and high production rate (approx. 120 million tonnes annual), its disposal constitutes a major problem in the aluminum industry.

Aluminum of Greece is a vertical integrated alumina refinery and aluminum smelter plant, where filter press technology is applied to transform the slurry into a filter cake with $25-28 \%$ moisture. The cake, called ferroalumina, is deposited temporarily in piles within the operation plant. Generally, bauxite residue either as slurry or as a filter cake is usually deposited at the sea, in dams, in natural and artificial ponds-as a lining to avoid disruption of aquifer-or in landfills. A strong interest in bauxite residue valorization has led to the development of new uses or applications of red mud: it is further processed for the extraction of iron, titanium, vanadium, chromium, aluminum, and rare earths [2] or it is used as a component in mixtures for the development of cement [3], mineral wool and fibers [4], ceramic foams [5], bricks [6], and ceramics [7].

In most of the aforementioned valorization techniques, production processes comprise a mixing and a heat treatment stage. In order to enhance the filter cake workability, and to render it suitable for direct exposure to temperatures higher than $800{ }^{\circ} \mathrm{C}$, its dewatering is inevitable, and thus, a drying stage prior to any further processing step is required. 
Filter cake drying process constitutes an essential preliminary processing stage with increased cost due to high energy demands that arise from the significantly high initial water content of the material. There is also one reason that necessitates the study of red mud drying; usually, red mud is temporarily arranged in piles in the plant and the initial moisture present acts as a binder of the particles, thus preventing dust generation and pneumatic transfer of the materials at nearby environment. However, as the surface moisture content decreases through evaporation process, especially during the summer, dust generation becomes inevitable. Water spraying is a common practice that is practiced in many refineries to avoid dust dissemination. It is thus important to study the drying process to determine the critical moisture ratio, above which the red mud consistency is attenuated, and dust formation and transfer to surroundings is favored.

Drying constitutes a complicated process due to the simultaneous heat and mass transfer and the effect of materials' physical properties. Modeling approach of drying process can provide detailed information concerning the effect of basic drying parameters, including process and material parameters on drying performance. The modeling results will be useful in designing a new, or improving an existing, drying equipment; reducing energy consumption; and overall increasing the drying efficiency. Thin-layer drying equations constitute an important tool in mathematical modeling of various materials' drying as they describe the drying phenomena in a unified way, regardless of the controlled mechanism, and they have found wide applications due to their ease of use; their applications are not only widespread in food and agricultural products, but have also been used in other organic (lignite [8]) and inorganic materials (plasters [9], minerals [10]) with satisfactory results. In comparison with classical complex distributed models (such as coupling coefficients and phenomenological approaches), these mathematical models require less data. Classical models take into account only the internal resistance to moisture transfer within the materials and calculate the heat and mass transfer equations as a function of position in the materials and the time, while the thin-layer models consider the external resistance to moisture transfer between the product and air. Thin-layer equations may be categorized to theoretical, semi-theoretical, and empirical models. Theoretical models interpret the sample drying phenomenon and can be used at all process conditions. However, they include many assumptions and may thus cause considerable errors. The most widely used theoretical models are derived from the Fick's second law of diffusion and Newton's law of cooling. Similarly, semitheoretical models are derived from the same laws or modifications of their simplified forms. They are easier and need fewer assumptions due to the usage of experimental data. On the other hand, they are valid only within the process conditions applied. The empirical models have also similar characteristics with semi-theoretical models. They strongly depend on the experimental conditions and give limited information about the drying behaviors of the product [11].

Effective moisture diffusivity $\left(D_{\text {eff }}\right)$ and activation energy $\left(E_{\mathrm{a}}\right)$ constitute important drying process parameters. $D_{\text {eff }}$ is related to the drying potential and is affected by both material and process parameters, while $E_{\mathrm{a}}$ is the minimum energy required for drying initialization. Most commonly, these drying parameters are determined under isothermal conditions by a two-step method: first, the $D_{\text {eff }}$ is determined from the drying curves using the Fick's second law and then the $E_{\mathrm{a}}$ and the pre-exponential factor are calculated through the correlation of $D_{\text {eff }}$ values in terms of drying temperature by the Arrhenius-type equation.

In the current research study, for the first time in the literature, a modeling approach for red mud filter cake drying is presented and thin-layer drying equations are implemented for this purpose. The kinetics of red mud moisture removal are investigated through thermogravimetric analysis, and the obtained experimental drying curves are compared with 10 thin-layer models' predictions, including theoretical, semi-theoretical, and empirical ones, scoping to select the most accurate one. The model parameter values are calculated in terms of drying temperature ranging between 50 and $250{ }^{\circ} \mathrm{C}$ in order to approach both artificial and natural drying conditions. Furthermore, the effective diffusion coefficient is calculated, and the energy barrier of red mud drying is determined through the calculation of drying activation energy.

\section{Materials and Methods}

\section{Greek Red Mud Characterization}

The current study has been performed to filter cake samples that were supplied by Aluminum of Greece; the samples have been obtained directly from the filter presses with initial moisture of $23 \%$ w.t. After sampling, the wet samples were kept in airtight samplers to avoid moisture removal until drying experiments were performed. Chemical composition of the red mud sample was identified using an Energy-Dispersive X-Ray Fluorescence instrument Xepos (SPECTRO A.I. GmbH Company); red mud mainly consists of iron and aluminum oxide and lower amounts of calcium, titanium, silicon, and sodium oxide (Table 1). Size distribution of the red mud grains sample was measured on a Malvern Laser Particle Analyzer, and was found to range between 0.1 and $100 \mu \mathrm{m}$, with $D 50$ being $2.3 \mu \mathrm{m}$ and $D 90$ being $23.7 \mu \mathrm{m} \quad$ (Fig. 1). 
Table 1 Chemical composition of filter cake (red mud) sample

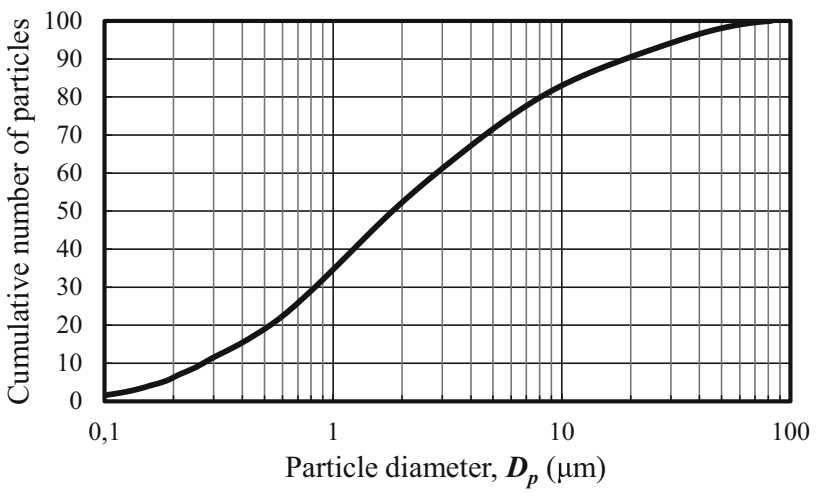

Fig. 1 Particle size distribution of filter cake sample

Mineralogical analysis was performed by X-Ray diffraction (XRD) on a SIEMENS D5000 diffractometer, and phases of hematite $\left(\mathrm{a}-\mathrm{Fe}_{2} \mathrm{O}_{3}\right)$, diaspore $(\mathrm{a}-\mathrm{AlO}(\mathrm{OH}))$, cancrinite $\left(\mathrm{Na}_{6} \mathrm{Ca}_{2} \mathrm{Al}_{6} \mathrm{Si}_{6} \mathrm{O}_{24}\left(\mathrm{CO}_{3}\right)_{2}\right)$, katoite, gibbsite $\left(\mathrm{Al}(\mathrm{OH})_{3}\right)$, and boehmite $(\gamma-\mathrm{AlO}(\mathrm{OH}))$ were identified (Fig. 2).

\section{Drying Experiments}

Isothermal drying experiments were performed on a Labsys TG Apparatus under He atmosphere (flowrate: $20 \mathrm{ml} \mathrm{min}^{-1}$, velocity: $0.188 \mathrm{~m} \mathrm{~s}^{-1}$ ) and various temperatures $50,75,100$,
150,200 , and $250{ }^{\circ} \mathrm{C}$. This wide range of drying temperature was chosen so as (1) to investigate the drying potential at temperature above and below the water boiling point, and (2) to approach the drying process under natural and artificial drying conditions. For each experiment, $80 \mathrm{mg}$ of filter cake mud was placed in a platinum cylindrical sampler of $3 \mathrm{~mm}$ diameter, and the temporal evolution of sample weight was recorded. All the drying experiments were conducted in triplicate and the average values of the moisture content at each value were used for drawing drying curves. Bibliographic data ensure that when red mud is heated up to $250{ }^{\circ} \mathrm{C}$, the observed weight loss is exclusively attributed to moisture removal (physically or chemically absorbed) [12].

Moisture ratio (MR) during drying is expressed using Eq. 1, where $M, M_{\mathrm{e}}$, and $M_{\mathrm{o}}$ denote actual, equilibrium, and initial moisture content, respectively.

$\mathrm{MR}=\frac{M-M_{e}}{M_{0}-M_{e}}$

Each drying experiment was completed when the mass loss rate approaches zero and the weight loss was $23 \%$ of the initial samples weight. In that case, the equilibrium moisture content equals 0 and thereby MR can be simplified to $M / M_{\mathrm{o}}$. The drying rate of filter cake was calculated using the following equation:

$\frac{\partial \mathrm{MR}}{\partial t}=-\frac{\mathrm{MR}_{n}-\mathrm{MR}_{n-1}}{t_{n}-t_{n-1}}$

\section{Thin-layer Modeling}

Ten widely used thin-layer models were employed for modeling filter cake drying curves under isothermal conditions and various drying temperatures, and they are presented in Table 2.

The models' consistency was studied using the following statistical tests: the coefficient of determination $\left(R^{2}\right.$, Eq. 3), the $\boldsymbol{F}$ value (Eq. 4$)$, and the reduced Chi-square $\left(\chi^{2}\right.$, Eq. 5). Non-linear regression analysis was performed using statistical software OriginPro 8.5.
Fig. 2 XRD pattern of red mud sample

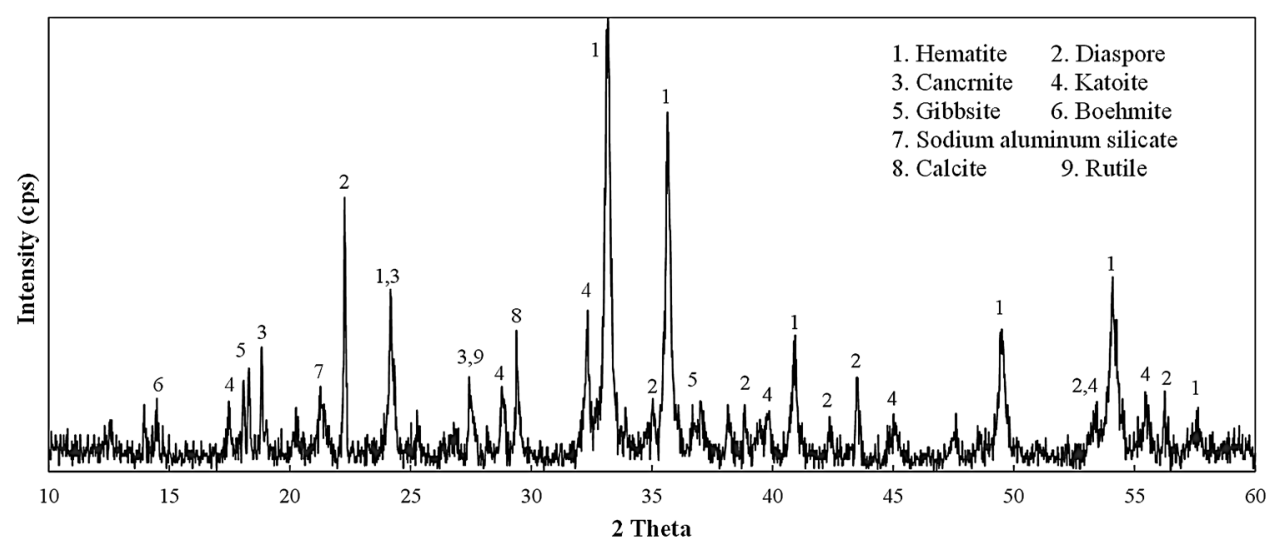


Table 2 Bibliographic thinlayer models applied to the drying curves

\begin{tabular}{llll}
\hline Model No. & Name & Formula & References \\
\hline 1 & Wang and Sight & $M R=1+a \cdot t+b \cdot t^{2}$ & {$[13]$} \\
2 & Newton & $M R=\exp (-k \cdot t)$ & {$[14]$} \\
3 & Henderson and Pabis & $M R=a \cdot \exp (-k \cdot t)$ & {$[15]$} \\
4 & Diffusion approach & $M R=a \cdot \exp (-k \cdot t)+(1-a) \cdot \exp (-k \cdot b \cdot t)$ & {$[16]$} \\
5 & Logarithmic & $M R=a \cdot \exp (-k \cdot t)+c$ & {$[17]$} \\
6 & Verma & $M R=a \cdot \exp (-k \cdot t)+(1-a) \cdot \exp (-g \cdot t)$ & {$[18]$} \\
7 & Page & $M R=\exp \left(-k \cdot t^{n}\right)$ & {$[19]$} \\
8 & Modified Page & $M R=\exp \left(-(k \cdot t)^{n}\right)$ & {$[20]$} \\
9 & Midilli et al. & $M R=a \cdot \exp \left(-k\left(t^{n}\right)\right)+b \cdot t$ & {$[22]$} \\
10 & Simplified Fick & $\left.M R=a \cdot \exp \left(-c\left(t \cdot L^{-2}\right)\right)\right)$ &
\end{tabular}

In Eq. 4, $\mathrm{MS}_{\text {treatment }}$ is the mean squares for treatment and $\mathrm{MS}_{\text {error }}$ is the mean squares for error, which are both formed by dividing the sum of squares by associated degrees of freedom, respectively.

\section{Effective Moisture Diffusivity and Activation Energy}

Information on the exact filter cake drying mechanism is limited, and due to the complexity of the process, a lumped value of diffusivity, called effective diffusivity, may be used to investigate the process potential in terms of drying temperature. Effective moisture diffusivity $\left(D_{\text {eff }}\right)$ describes all possible mechanisms of mass transfer within materials, such as liquid diffusion, vapor diffusion, surface diffusion, and capillary flow, while its value is affected by various parameters, namely material composition, moisture content, and morphology. In the current study, it was assumed that the filter cake sample shape is cylindrical; although the sample consists of spherical particles of $2.3 \mu \mathrm{m}$ in mean diameter $(D 50)$, due to their tiny size and slurry nature, the sample occupied the entire crucible space forming a cylinder. The samples retain their compact cylindrical shape during and after the drying experiment, so it was decided that for the calculation of effective diffusivity values through the Fick's second law, the geometrical characteristics of the samples would be that of a cylinder with diameter of $3 \mathrm{~mm}$. Actually, the aforementioned assumption can be safely made due to the fact that the high initial water content and the fineness of the material lead to
Fig. 3 Temporal evolution of filter cake moisture ratio at different drying temperatures

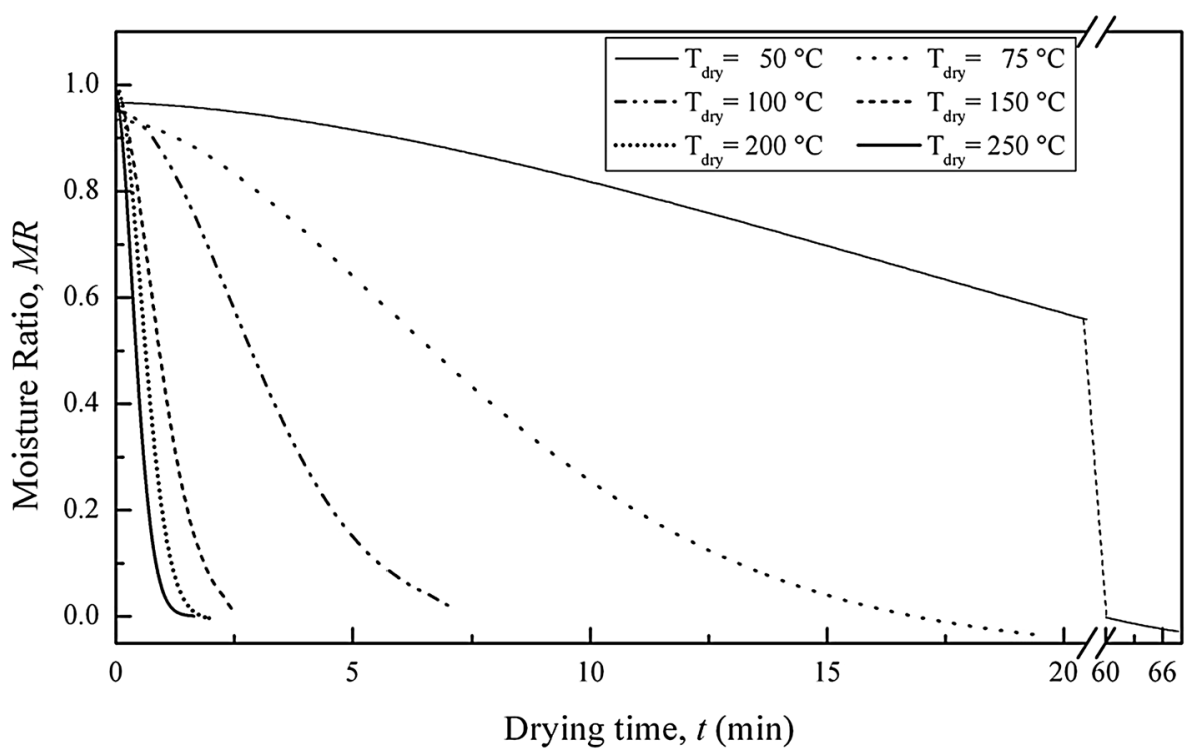


Fig. 4 Drying rates of filter cake at different drying temperatures

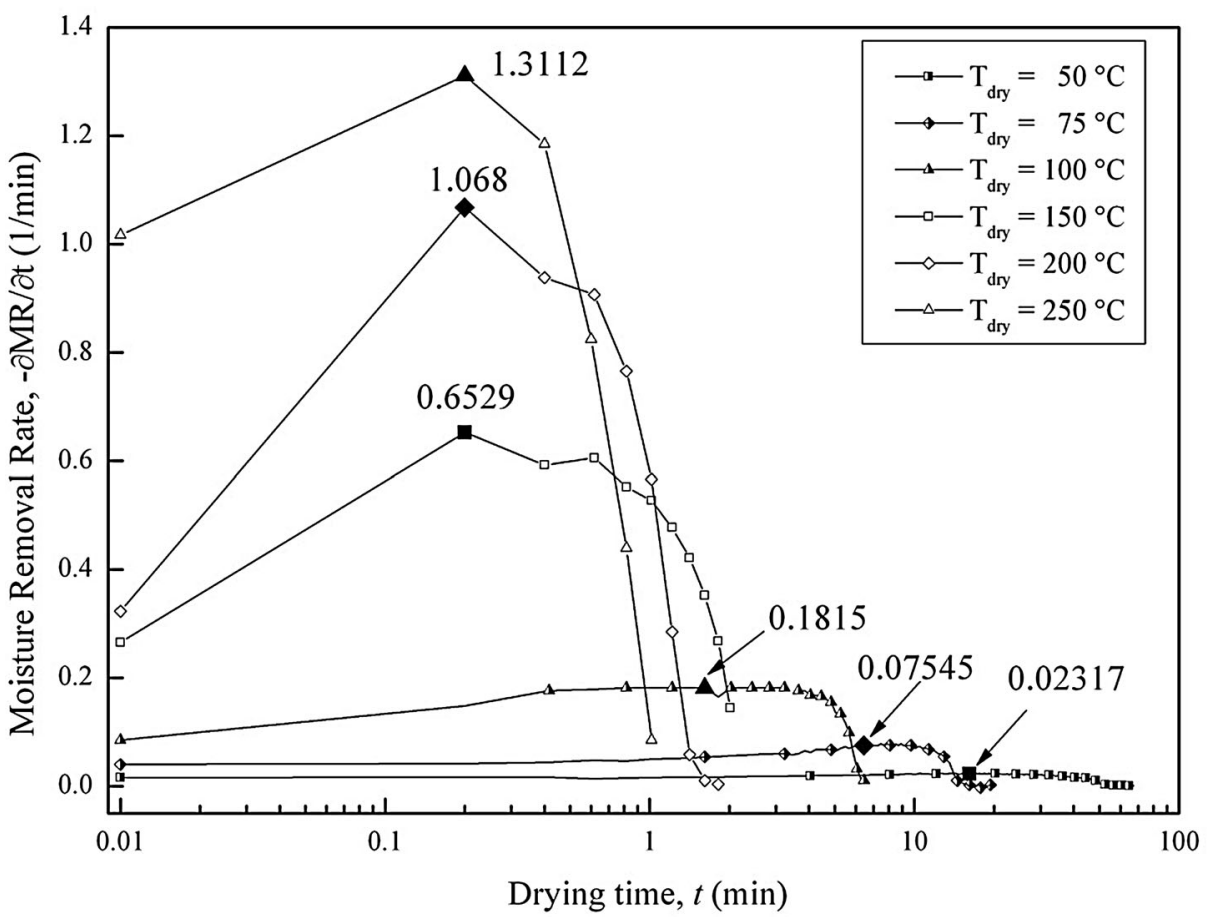

the formation of compact agglomerates and it is realistic to investigate the filter cake drying process in this form.

$\frac{\partial M}{\partial t}=\frac{1}{r}\left[\frac{\partial}{\partial r}\left(D \cdot r \cdot \frac{\partial M}{\partial r}\right)+\frac{\partial}{\partial z}\left(D \cdot r \cdot \frac{\partial M}{\partial z}\right)\right]$

$\mathrm{MR}=\frac{M-M_{e}}{M_{i}-M_{e}}=\sum_{n=1}^{\infty} \frac{4}{\beta_{n}^{2}} \times\left(\frac{-\beta_{n}^{2} \cdot D_{e f f}}{r_{c}^{2}} \cdot t\right)$

$\mathrm{MR}=\frac{M-M_{e}}{M_{i}-M_{e}}=\frac{4}{\beta_{1}^{2}} \exp \left(-\frac{\beta_{1}^{2} \cdot D_{e f f} \cdot t}{r_{c}^{2}}\right)$

According to the Fick's second law for non-steady-state diffusion, and assuming a cylindrical shape, the diffusion is expressed by [23]

$\frac{\partial M}{\partial t}=\frac{1}{r_{c}}\left[\frac{\partial}{\partial r}\left(D_{e f f} \cdot r_{c} \cdot \frac{\partial M}{\partial r}\right)+\frac{\partial}{\partial z}\left(D_{e f f} \cdot r_{c} \cdot \frac{\partial M}{\partial z}\right)\right]$

where $r_{\mathrm{c}}$ is the cylinder diameter $(m)$ and $D_{\text {eff }}$ is the diffusion coefficient $\left(\mathrm{m}^{2} \mathrm{~s}^{-1}\right)$. Under the assumption of uniform initial moisture content and constant effective diffusivity throughout the sample, the analytical solution of Eq. 9 is given by

$M R=\frac{M-M_{e}}{M_{i}-M_{e}}=\sum_{n=1}^{\infty} \frac{4}{\beta_{n}^{2}} \times\left(\frac{-\beta_{n}^{2} \cdot D_{e f f}}{r_{c}^{2}} \cdot t\right)$

where $\beta_{\mathrm{n}}$ are the roots of Bessel function and $t$ is time $(s)$. For long drying times, the first term of the series in Eq. 10 can be considered; thus, the solution of the Fick's equation becomes
$M R=\frac{M-M_{e}}{M_{i}-M_{e}}=\frac{4}{\beta_{1}^{2}} \exp \left(-\frac{\beta_{1}^{2} \cdot D_{e f f} \cdot t}{r_{c}^{2}}\right)$

where $\beta_{1}=2.4048$.

This simplified solution can be written in logarithmic form (Eq. 12), where $B$ is the line slope that is related to the effective diffusivity:

$\ln \mathrm{MR}=A-B \times t$

$B=\frac{\beta_{i}^{2} \cdot D_{\mathrm{eff}}}{r_{c}^{2}}$

The effective diffusivity was calculated using Eq. (13), using slopes derived from the linear regression of $\ln (\mathrm{MR})$ against time. The impact of drying temperature on effective diffusivity is generally described by Arrhenius-type relationship.

$D_{\text {eff }}=D_{0} \exp \left(-\frac{E_{a}}{R \cdot T}\right)$

where $D_{0}$ is the diffusivity constant equivalent to the diffusivity value at infinitive temperature (also called preexponential factor of Arrhenius equation) $\left(\mathrm{m}^{2} \mathrm{~s}^{-1}\right), E_{a}$ is the drying activation energy $\left(\mathrm{kJ} \mathrm{mol}^{-1}\right), R$ is the universal gas constant $\left(8.3143 \mathrm{~J} \mathrm{~mol}^{-1} \mathrm{~K}^{-1}\right)$, and $T$ is the absolute temperature $(\mathrm{K})$. Activation energy can be determined from the slope of Arrhenius plot of $\ln (D)$ versus $T^{-1}$, while the intercept coincides with $D_{O}$ value. 
Table 3 The applied thin-layer models constants and statistical parameters for the simulation of the filter cake moisture ratio evolution during drying

\begin{tabular}{|c|c|c|c|c|c|c|c|c|c|c|c|}
\hline \multirow[t]{2}{*}{ Model } & \multirow{2}{*}{$\begin{array}{l}\text { Drying } \\
\text { temperature } \\
T_{d r y}\left({ }^{\circ} \mathrm{C}\right)\end{array}$} & \multicolumn{7}{|c|}{ Models coefficients } & \multicolumn{3}{|c|}{ Statistic error } \\
\hline & & $\mathrm{a}$ & $\mathrm{b}$ & $\mathrm{C}$ & $\mathrm{g}$ & $\mathrm{k}$ & $\mathrm{L}$ & $\mathrm{n}$ & $\mathrm{R}^{2}$ & F-value & $\chi^{2}\left(\cdot 10^{3}\right)$ \\
\hline \multirow[t]{6}{*}{1} & 50 & $-4.39 \mathrm{E}-04$ & $4.38 \mathrm{E}-08$ & & & & & & 0.988 & $30,576.40$ & 1.30 \\
\hline & 75 & -0.00152 & $5.25 \mathrm{E}-07$ & & & & & & 0.987 & 7860.09 & 1.44 \\
\hline & 100 & -0.00368 & $3.31 \mathrm{E}-06$ & & & & & & 0.985 & 3128.17 & 1.65 \\
\hline & 150 & -0.01061 & $2.67 \mathrm{E}-05$ & & & & & & 0.982 & 939.18 & 2.00 \\
\hline & 200 & -0.01666 & $6.67 \mathrm{E}-05$ & & & & & & 0.977 & 429.05 & 3.24 \\
\hline & 250 & -0.02085 & $1.00 \mathrm{E}-04$ & & & & & & 0.961 & 216.31 & 4.56 \\
\hline \multirow[t]{6}{*}{2} & 50 & & & & & $6.29 \mathrm{E}-04$ & & & 0.926 & 9542.98 & 8.08 \\
\hline & 75 & & & & & 0.00219 & & & 0.923 & 2626.61 & 8.38 \\
\hline & 100 & & & & & 0.00519 & & & 0.937 & 445.70 & 6.93 \\
\hline & 150 & & & & & 0.0158 & & & 0.951 & 651.89 & 5.63 \\
\hline & 200 & & & & & 0.02381 & & & 0.934 & 294.44 & 9.17 \\
\hline & 250 & & & & & 003412 & & & 0.966 & 485.72 & 4.07 \\
\hline \multirow[t]{6}{*}{3} & 50 & 1.17091 & & & & $7.28 \mathrm{E}-04$ & & & 0.952 & 7416.60 & 5.26 \\
\hline & 75 & 1.14163 & & & & 0.00248 & & & 0.941 & 1735.96 & 6.40 \\
\hline & 100 & 1.16787 & & & & 0.00593 & & & 0.957 & 1072.51 & 4.73 \\
\hline & 150 & 1.13527 & & & & 0.01756 & & & 0.963 & 442.34 & 4.19 \\
\hline & 200 & 1.13475 & & & & 0.02634 & & & 0.945 & 179.59 & 7.59 \\
\hline & 250 & 1.07522 & & & & 0.03615 & & & 0.968 & 263.19 & 3.77 \\
\hline \multirow[t]{6}{*}{4} & 50 & 1.17664 & $1.03 \mathrm{E}+06$ & & & $7.32 \mathrm{E}-04$ & & & 0.953 & 5017.70 & 5.19 \\
\hline & 75 & 1.15888 & $1.05 \mathrm{E}+06$ & & & 0.00251 & & & 0.943 & 1189.95 & 6.24 \\
\hline & 100 & 126.36577 & 1.00872 & & & 0.01098 & & & 0.989 & 2714.19 & 1.27 \\
\hline & 150 & 226.41257 & 1.00497 & & & 0.03384 & & & 0.994 & 1905.89 & 0.66 \\
\hline & 200 & 263.13665 & 1.00498 & & & 0.05496 & & & 0.993 & 1029.60 & 0.91 \\
\hline & 250 & 221.32301 & 1.00498 & & & 0.07237 & & & 0.996 & 1567.62 & 0.43 \\
\hline \multirow[t]{6}{*}{5} & 50 & 1.46661 & & -0.38672 & & $3.82 \mathrm{E}-04$ & & & 0.989 & 21041.70 & 1.26 \\
\hline & 75 & 1.49744 & & -0.44726 & & 0.00121 & & & 0.984 & 4312.29 & 1.75 \\
\hline & 100 & $1.2325 \mathrm{~S}$ & & -0.1102 & & 000459 & & & 0.974 & 1171.46 & 2.92 \\
\hline & 150 & 1.18183 & & -0.07147 & & 0.01476 & & & 0.974 & 413.78 & 3.01 \\
\hline & 200 & 1.21794 & & -0.10874 & & 0.02074 & & & 0.960 & 164.911 & 5.57 \\
\hline & 250 & 1.11066 & & -0.04651 & & 0.03211 & & & 0.973 & 204.96 & 3.24 \\
\hline \multirow[t]{6}{*}{6} & 50 & 1.17668 & & & $2.74 \mathrm{E}+06$ & $7.32 \mathrm{E}-04$ & & & 0.953 & 5017.70 & 5.19 \\
\hline & 75 & 1.1588 & & & 4.63101 & 0.00251 & & & 0.943 & 1189.95 & 6.24 \\
\hline & 100 & 221.33306 & & & 0.01105 & 0.011 & & & 0.989 & 2714.25 & 1.27 \\
\hline & 150 & 224.47125 & & & 0.03401 & 003384 & & & 0.994 & 1905.89 & 0.66 \\
\hline & 200 & 260.72888 & & & 0.05523 & 0.05495 & & & 0.993 & 1029.60 & 0.91 \\
\hline & 250 & 219.16482 & & & 0.07273 & 0.07237 & & & 0.996 & 1567.62 & 0.43 \\
\hline \multirow[t]{6}{*}{7} & 50 & & & & & $5.07 \mathrm{E}-06$ & & 16421 & 0.994 & 62716.81 & 0.63 \\
\hline & 75 & & & & & $4.78 \mathrm{E}-05$ & & 0.05122 & 0.986 & 7271.15 & 1.56 \\
\hline & 100 & & & & & $1.01 \mathrm{E}-04$ & & 1.72242 & 0.995 & 9456.79 & 0.55 \\
\hline & 150 & & & & & $7.63 \mathrm{E}-04$ & & 1.69819 & 0.998 & 9100.68 & 0.21 \\
\hline & 200 & & & & & $673 \mathrm{E}-04$ & & 1.91132 & 0.999 & 7767.53 & 0.18 \\
\hline & 250 & & & & & 000358 & & 1.63025 & 0.999 & 7250.41 & 0.14 \\
\hline \multirow[t]{4}{*}{8} & 50 & & & & & $5.95 \mathrm{E}-04$ & & 1.68616 & 0.994 & 64652.12 & 0.62 \\
\hline & 75 & & & & & 0.00206 & & 1.66467 & 0.986 & 7414.58 & 1.53 \\
\hline & 100 & & & & & 0.0048 & & 1.72242 & 0.995 & 9456.79 & 0.55 \\
\hline & 150 & & & & & 0.01459 & & 1.69819 & 0.998 & 9100.68 & 0.21 \\
\hline
\end{tabular}


Table 3 continued

\begin{tabular}{|c|c|c|c|c|c|c|c|c|c|c|c|}
\hline \multirow[t]{2}{*}{ Model } & \multirow{2}{*}{$\begin{array}{l}\text { Drying } \\
\text { temperature } \\
T_{d r y}\left({ }^{\circ} \mathrm{C}\right) \\
\end{array}$} & \multicolumn{7}{|c|}{ Models coefficients } & \multicolumn{3}{|c|}{ Statistic error } \\
\hline & & $\mathrm{a}$ & $\mathrm{b}$ & $\mathrm{C}$ & $\mathrm{g}$ & k & $\mathrm{L}$ & $\mathrm{n}$ & $\mathrm{R}^{2}$ & F-value & $\chi^{2}\left(\cdot 10^{3}\right)$ \\
\hline & 200 & & & & & 0.0219 & & 1.92413 & 0.999 & 7807.33 & 0.18 \\
\hline & 250 & & & & & 003159 & & 1.63659 & 0.999 & 7263.31 & 0.14 \\
\hline \multirow[t]{6}{*}{9} & 50 & 0.9666 & $-1.22 E-05$ & & & $3.76 E-06$ & & 1.6646 & 0.998 & 89494.71 & 0.22 \\
\hline & 75 & 0.93438 & $-4.71 E-05$ & & & $1.67 E-05$ & & 1.74711 & 0.994 & 8755.27 & 0.65 \\
\hline & 100 & 0.95253 & $-7.85 E-06$ & & & $4.14 E-05$ & & 1.87511 & 0.996 & 6513.10 & 0.40 \\
\hline & 150 & 0.914 & $-1.20 \mathrm{E}-05$ & & & $4.00 E-04$ & & 1.8387 & 0.998 & 4659.83 & 0.20 \\
\hline & 200 & 1.0004 & $-4.34 \mathrm{E}-05$ & & & $6.99 E-04$ & & 1.89937 & 0.999 & 3501.81 & 0.20 \\
\hline & 250 & 0.97924 & $9.39 E-06$ & & & 0.00199 & & 1.79357 & 0.993 & 395.11 & 1.77 \\
\hline \multirow[t]{6}{*}{10} & 50 & 1.17102 & & $4.90 \mathrm{E}-05$ & & & 0.25944 & & 0.952 & 4929.59 & 5.28 \\
\hline & 75 & 1.14987 & & 0.00857 & & & 1.85888 & & 0.941 & 1145.25 & 6.47 \\
\hline & 100 & 1.16799 & & 0.04968 & & & 2.89353 & & 0.956 & 702.24 & 4.81 \\
\hline & 150 & 1.13547 & & $2.75 \mathrm{E}-05$ & & & 0.03956 & & 0.961 & 280.85 & 4.40 \\
\hline & 200 & 1.13475 & & 1.26239 & & & 6.92329 & & 0.940 & 109.75 & 8.28 \\
\hline & 250 & 1.07522 & & 1.45191 & & & 6.33781 & & 0.965 & 159.51 & 4.14 \\
\hline
\end{tabular}

The data of the most accurate model are made in bold

Table 4 Coefficients for the calculation of $a, k, n, b$ constants of Eq. 15

\begin{tabular}{|c|c|c|c|c|c|c|}
\hline & \multicolumn{5}{|c|}{$a, k, n, b\left(50<T_{d r y}<250^{\circ} C\right)=a_{1} T^{5}+a_{2} T^{4}+a_{3} T^{3}+a_{4} T^{2}+a_{5} T+a_{6}$} & \multirow{2}{*}{$\begin{array}{l}R^{2}=1.000 \\
a_{6}\end{array}$} \\
\hline & $a_{1}$ & $a_{2}$ & $a_{3}$ & $a_{4}$ & $a_{5}$ & \\
\hline$a$ & $-5.11366 \mathrm{E}-11$ & $3.58516 \mathrm{E}-08$ & $-9.40717 \mathrm{E}-06$ & $1.15249 \mathrm{E}-03$ & $-6.58326 \mathrm{E}-02$ & 2.34481 \\
\hline$b$ & $-3.14360 \mathrm{E}-14$ & $2.44190 \mathrm{E}-11$ & $-7.12358 \mathrm{E}-09$ & $9.62709 \mathrm{E}-07$ & $-5.93517 \mathrm{E}-05$ & $1.29626 \mathrm{E}-03$ \\
\hline$n$ & 0 & 0 & $-2 \mathrm{E}-05$ & $2.17 \mathrm{E}-03$ & -0.11553 & 3.87037 \\
\hline$k$ & $1.11147 \mathrm{E}-13$ & $-7.38123 \mathrm{E}-11$ & $1.83374 \mathrm{E}-08$ & $-2.07416 \mathrm{E}-06$ & $1.07835 \mathrm{E}-04$ & $-2.06820 \mathrm{E}-03$ \\
\hline
\end{tabular}

\section{Results and Discussion}

\section{Experimental Drying Curves and Evaluation of Drying Models}

Drying curves (moisture ratio versus time) and drying rate curves (drying rate versus time) are shown in Figs. 3 and 4, respectively. As can be observed, the total drying time reduces significantly as drying temperature increases. For temperatures below the water boiling point, the drying times are $1 \mathrm{~h}$ and $20 \mathrm{~min}$ for drying temperatures 50 and $75^{\circ} \mathrm{C}$, respectively; it is noteworthy that an increase of drying temperature by only $25{ }^{\circ} \mathrm{C}$ results in the reduction of drying time by $40 \mathrm{~min}$. A further significant reduction of drying time occurs when drying temperature exceeds the water boiling point. In such cases (drying temperatures 150,200 , and $250{ }^{\circ} \mathrm{C}$ ), drying time falls below $2.5 \mathrm{~min}$. As the drying temperature increases from 50 to $250{ }^{\circ} \mathrm{C}$, the maximum drying rate values increase, while the peaks are observed sooner. Normally, the moisture migration increases as the drying temperature increases. The maximum moisture drying rates are observed at the initial stage of drying process, namely the warm-up period, and this is attributed to the increased moisture evaporation from filter cake due to the increasing temperature in the beginning of the process. The phenomenon is more intense when the drying temperature exceeds the water boiling temperature. It is important to note that the rising rate period lasts much less than the entire drying process at all studied drying temperatures, and this demonstrates that the thermal lag at the beginning of the drying experiments can practically be assumed imperceptible. The second wide stage of the drying process is the falling rate period. The heating rate during the falling rate period was clearly lower in comparison to the warm-up stage, when drying temperature exceeds $100{ }^{\circ} \mathrm{C}$. Since large amount of water was already removed mainly from the sample surface, the vapor pressure during the falling rate period is significantly smaller. The absence of a distinct constant rate stage indicates that the internal moisture diffusion process progressively becomes the most important drying controlling factor [24]. On the other hand, when the drying temperature is up to 
$100{ }^{\circ} \mathrm{C}$, the curve is much more smooth while a wide plateau is observed throughout the drying time. In these cases, the sample experiences first a moisture removal from their surface (outer layer), where vapor migration to the environment is unobstructed. Once the majority of surface moisture has been evaporated, the open capillaries allow the escape of the inner layer water vapors. Moreover, the water vapor pressure at such temperatures is too low to allow its migration from the sample core to the outer surface, especially when the outer surface capillaries are still blocked with water.

Ten bibliographic thin-layer models were employed to describe the filter cake drying kinetics, while the models' consistency was tested through four statistical error factors. Models' coefficients and statistical test results are depicted in Table 3. The criterion for selection of the best model describing the drying kinetics was the model with higher $R^{2}$ and $F$ value, and the lowest $\chi^{2}$ average values. In case of Midilli et al.'s model, mean values of $R^{2}, F$ value, and $\chi^{2}$ were found to be $0.996,18886.64$, and 0.00057 , respectively. Midilli et al.'s model constitutes the most accurate one for the simulation of moisture removal through isothermal heating of filter cake in the temperature range of $50-250{ }^{\circ} \mathrm{C}$.

The temporal evolution of moisture content of filter cake can be accurately simulated using Eq. 15 , while the equation coefficient values $(a, b, n, k)$ in terms of drying temperature (between 50 and $250{ }^{\circ} \mathrm{C}$ ) can be calculated using the equation that is depicted in Table 4:

$\operatorname{MR}(a, k, n, b)=a \cdot \exp \left(-k \cdot t^{n}\right)+b \cdot t$

In order to validate the established model, the experimental moisture ratio values were compared with the predicted values that were derived by the application of Eq. 15 and the results are illustrated in Fig. 5. The values are distributed around the $45^{\circ}$ oblique line, indicating that the Midilli et al.'s model is suitable for simulating the filter cake drying kinetics throughout the entire moisture ratio and the studied drying temperatures.

\section{Apparent Diffusion Coefficient and Activation Energy}

The calculated values of effective diffusivity in terms of drying temperature are presented in Table 5. All trend lines, regression values $\left(R^{2}\right)$ exceeded 0.9. Effective diffusivities of filter cake drying range between $0.3510 \times 10^{-9}$ and $21.3951 \times 10^{-9}\left(\mathrm{~m}^{2} \mathrm{~s}^{-1}\right)$ in the temperature range of $50-250{ }^{\circ} \mathrm{C}$. The increased values of $D_{\text {eff }}$ when drying temperature exceeds $100{ }^{\circ} \mathrm{C}$ directly affect the process potential. Normally, when sample temperature exceeds the water boiling point, vapor pressure increases significantly resulting in an increase in the mass transport

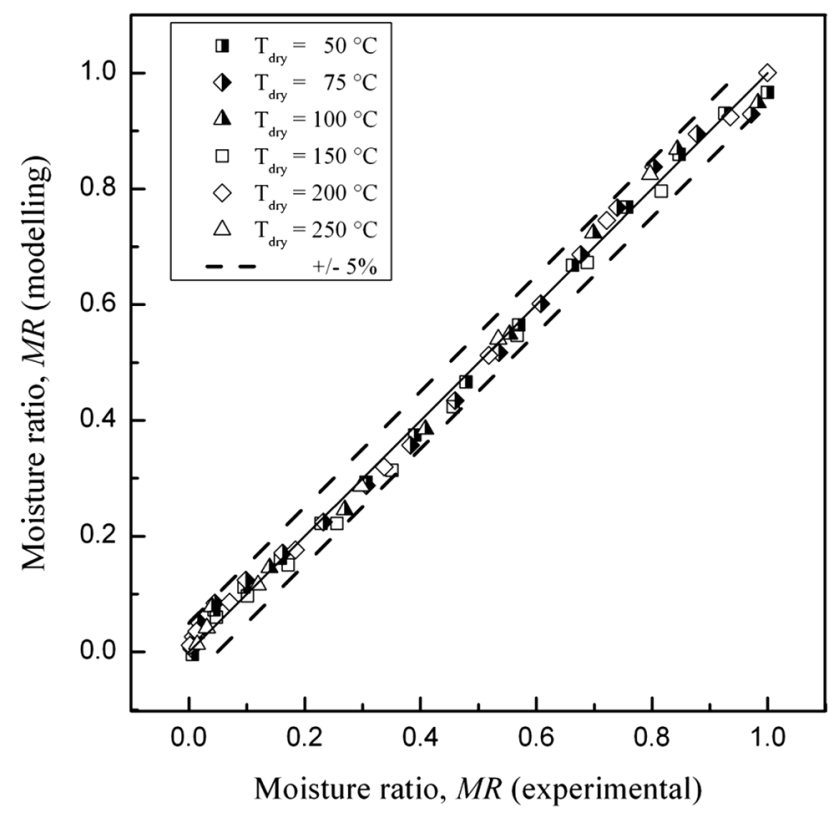

Fig. 5 Predicted MR by Midilli et al.'s model versus experimental MR at all drying temperatures studied and throughout the entire MR range

Table 5 Effective diffusivity values of filter cake throughout the studied drying temperature range

\begin{tabular}{lc}
\hline Drying temperature $T_{d r y}\left({ }^{\circ} \mathrm{C}\right)$ & $\begin{array}{l}\text { Effective diffusivity } \\
D_{\text {eff }} \times 10^{9}\left(\mathrm{~m}^{2} \mathrm{~s}^{-1}\right)\end{array}$ \\
\hline 50 & 0.3510 \\
75 & 1.2448 \\
100 & 2.4896 \\
150 & 7.8967 \\
200 & 13.5762 \\
250 & 21.3951 \\
\hline
\end{tabular}

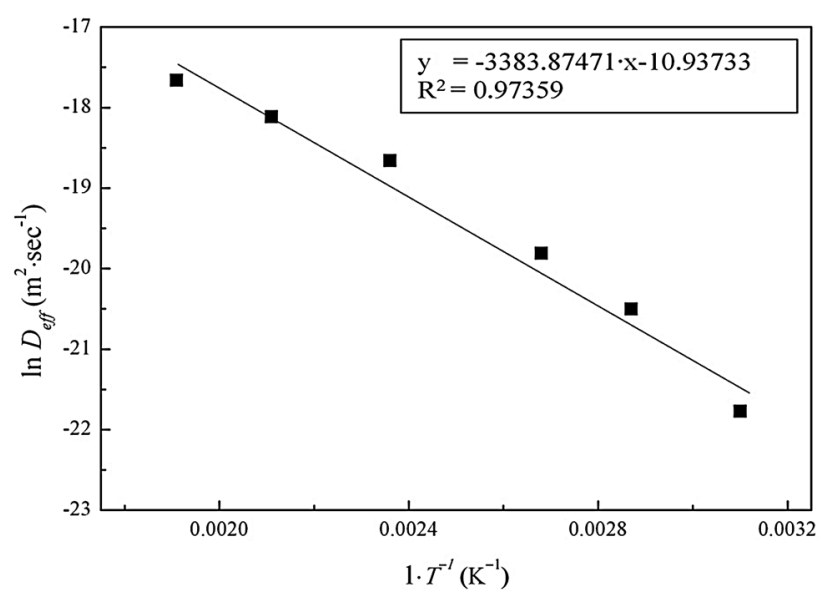

Fig. 6 Arrhenius plot relationship of $D_{\text {eff }}$ and drying temperature 
rate. It has to be noted that the increase of drying temperature from 50 to $150{ }^{\circ} \mathrm{C}$ results in a significant increase in $D_{\text {eff }}$ value (from 0.3510 to $7.8967 \times 10^{-9} \mathrm{~m}^{2} \mathrm{~s}^{-1}$ ).

According to Arrhenius plot (Fig. 6), the $E_{\mathrm{a}}$ and $D_{0}$ were found to have values of $28.133 \mathrm{~kJ} \mathrm{~mol}^{-1}$ and $1.7782 \times 10^{-5} \mathrm{~m}^{2} \mathrm{~s}^{-1}$, respectively.

\section{Conclusions}

In the current study, the drying behavior of bauxite residue obtained from the filter presses of Aluminum of Greece S.A. was investigated. Modeling of drying kinetics was performed through thin-layer model; Midilli et al.'s model can adequately describe filter cake drying under isothermal conditions and drying temperatures ranging between 50 and $250{ }^{\circ} \mathrm{C}$. The proposed equation enables the simulation of the temporal evolution of red mud filter cake moisture content under isothermal drying throughout the studied temperature range with considerable accuracy. The diffusion coefficient ranges between $0.3510 \times 10^{-9}$ and $21.3951 \times 10^{-9} \mathrm{~m}^{2} \mathrm{~s}^{-1}$ over a wide temperature range of 50-250 ${ }^{\circ} \mathrm{C}$. The activation energy for moisture diffusion was found to be $28.133 \mathrm{~kJ} \mathrm{~mol}^{-1}$. The drying parameters that were calculated here will be used on an ongoing research study which focuses on macroscopic modeling of red mud filter cake pile drying under physical conditions, where among others, meteorological data will be taken into consideration.

\section{References}

1. Balomenos E, Gianopoulou I, Panias D, Paspaliaris I, Perry K, Boufounos D (2011) Efficient and complete exploitation of the bauxite residue (red mud) produced in the Bayer process. In: GDMB (ed) Proceedings of EMC, vol 3, Germany, pp 745-758

2. http://www.redmud.org (Accessed in 10 September 2015)

3. Liu X, Zhang N (2011) Utilization of red mud in cement production: a review. Waste Manag Res 29:1053-1063

4. Balomenos E, Giannopoulou I, Gerogiorgis D, Panias D, Paspaliaris I (2014) Resource-efficient and economically viable pyrometallurgical processing of industrial ferrous by-products. Waste Biomass Volar 5:333-342
5. Chen X, Lu A, Qu G (2013) Preparation and characterization of foam ceramics from red mud and fly ash using sodium silicate as foaming agent. Ceram Int 39:1923-1929

6. He H, Yue Q, Su Y, Gao B, Gao Y, Wand YJ, Yu H (2012) Preparation and mechanism of the sintered bricks produced from Yellow River silt and red mud. J Hazard Mater 203-204:53-61

7. Pérez-Villarejo L, Corpas-Iglesias FA, Martinez-Martinez S, Artiaga R, Pascual-Cosp J (2012) Manufacturing new ceramic materials from clay and red mud derived from the aluminium industry. Constr Build Mater 35:656-665

8. Zhu J-F, Liu J-Z, Wu J-H, Cheng J, Zhou J-H, Cen KF (2015) Thin-layer drying characteristics and modelling of Ximeng lignite under microwave irradiation. Fuel Process Technol 130:62-70

9. Pillai MG (2012) Thin layer drying kinetics, characteristics and modelling of plaster of paris. Chem Eng Res Des 91:1018-1027

10. Sander A, Kardum JP (2009) Experimental validation of thinlayer drying models. Chem Eng Technol 32:590-599

11. Erbay Z, Icier F (2010) A review of thin layer draying of foods: theory, modeling, and experimental results. Crit Rev Food Sci Nutr 50:441-464

12. Agatzini-Leonardou BS, Oustadakis P, Tsakiridis PE, Markopoulos C (2008) A Titanium leaching from red mud by diluted sulfuric acid at atmospheric pressure. J Hazard Mater 157:579-586

13. Wang CV, Singh RP, (1978) A single thin layer drying equation for drying rough rice. Trans. Am. Soc. Agric. Eng. Paper, No. 783001, St. Joseph, Michigan

14. Lewis WK (1921) The rate of drying of solid materials. J Ind Eng $13: 427-443$

15. Henderson SM, Pabis S (1961) Grain drying theory. II. Temperature effects on drying coefficients. J Agric Eng Res 6:169-174

16. Yaldız O, Ertekin C (2001) Thin layer solar drying of some vegetables. Drying Technol 19:583-596

17. Rahman MS, Perera CO, Thebaud C (1998) Desorption isotherm and heat pump drying kinetics of peas. Food Res Int 30:485-491

18. Verma LR, Bucklin RA, Endan JB, Written FT (1985) Effects of drying air parameter on rice drying models. Trans Am Soc Agric Eng 28:296-301

19. Page G, (1949). Factors influencing the maximum rates of airdrying shelled corn in thin layers, M.S. Thesis. Lafayette, Purdue University West Lafayette, Indiana

20. Overhults DG, White GM, Hamilton HE, Ross IJ (1973) Drying soybeans with heated air. Trans Am Soc Agric Eng 16:112-113

21. Midilli A, Kucuk H, Yapar Z (2002) A new model for singlelayer drying. Drying Technol 20:1503-1513

22. Diamante LM, Munro PA (1991) Mathematical modeling of hot air drying of sweet potato slices. Int J Food Sci Techol 26:99-109

23. Crank J (1975) The mathematics of diffusion, 2nd edn. Oxford University Press, England

24. Belhamri A (2003) Characterization of the first falling rate period during drying of porous material. Drying Technol 21:1235-1252 